\title{
PREPARAÇÃO DE NANOESTRUTURAS MAGNETO-FLUORESCENTES A PARTIR DE FERROFLUIDO REVESTIDO COM POLIANILINA E PONTOS QUÂNTICOS
}

\author{
Mariana P. Cabrera ${ }^{1 *}$, Camila M. C. M. Silva ${ }^{1}$, Paulo Euzébio Cabral Filho ${ }^{1}$, Luiz B. Carvalho Jr. ${ }^{2}$, \\ Beate S. Santos ${ }^{3}$, Giovannia A. L. Pereira ${ }^{4}$, Adriana Fontes ${ }^{1}$ \\ ${ }^{1}$ Departamento de Biofísica e Radiobiologia, UFPE; ${ }^{2}$ Departamento de Bioquímica, UFPE; ${ }^{3}$ Departamento de Ciências Farmacêuticas, UFPE; \\ ${ }^{4}$ Departamento de Química Fundamental, UFPE \\ *marian.br09@gmail.com
}

\begin{abstract}
INTRODUÇÃO
Nos últimos anos, sistemas bimodais têm recebido destaque em biomedicina devido à versatilidade de aplicações, por exemplo, para obtenção de imagens por ressonância magnética (IRM) e por fluorescência. As nanopartículas de óxido de ferro, especialmente as de magnetita $\left(\mathrm{Fe}_{3} \mathrm{O}_{4}\right)$, apresentam elevada potencialidade para essa aplicação (Figura 1). A IRM é considerada uma das mais poderosas técnicas não invasivas para se obter informações detalhadas sobre estruturas anatômicas e processos funcionais (Bairagi et al., 2012, Maidment, 2010). Porém, devido à baixa sensibilidade dessa técnica, muitas vezes se faz necessário a utilização de agentes de contraste (ACs) para se aprimorar o realce das estruturas de interesse. Nesse contexto, as nanopartículas de ó xidos de ferro já são utilizadas clinicamente como ACs para se obter imagens com contraste negativo (Pereira et al., 2015).

Compostos fluorescentes tais como os nanocristais de semicondutores, ou pontos quânticos (PQs), são também ferramentas importantes para a investigação de assinaturas quí micas em estruturas biológicas. A alta sensibilidade da fluorescê ncia permite a detecção de pequenas quantidades de espécies específicas presentes em sistemas biológicos com resolução celular e molecular (Cabral Filho et al. 2016). Por outro lado, os PQs devem apresentar uma estrutura otimizada para que possam ser aplicados como marcadores biológicos, onde (1) o núcleo da nanopartícula determina sua emissão, (2) a camada de passivação determina a intensidade da emissão e a fotoestabilidade e, por fim, (3) a camada orgânica mais externa determina a sua estabilidade química e o grau de funcionalidade em relação à marcação do sistema biológico de interesse, além disso a estrutura dos PQs pode ser ainda mais complexa para aumentar a especificidade desse marcador como, por exemplo, conjugando a proteínas e outras biomoléculas (Santos et al., 2008). Dessa forma, a investigação de técnicas de sínteses para a obtenção de sistemas nanoestruturados com propriedades magnéticas e fluorescentes poderá auxiliar a medicina propiciando um maior e mais completo conhecimento de processos biológicos.

O presente trabalho teve como objetivo preparar nanoestruturas fluorescentes-magnéticas, a partir de nanopartículas de magnetita em suspensão (ferrofluido, FF) e pontos quânticos (PQs) de telureto de cádmio estabilizados com ácido mercaptosuccinico (CdTe-AMS), com potencialidades de aplicação para aquisição de sinais fluorescentes e magnéticos.
\end{abstract}

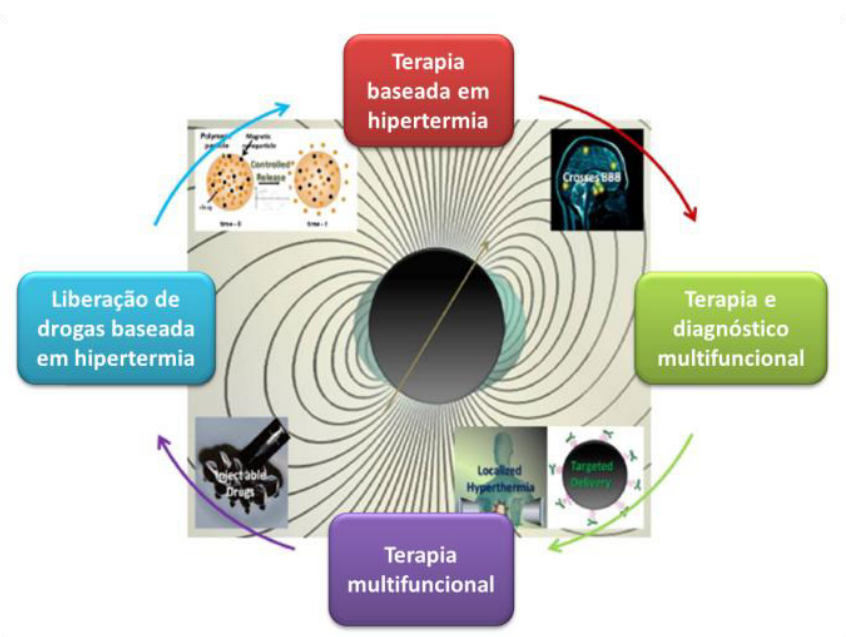

Figura 1. Principais aplicações de nanomateriais magnéticos para terapia e diagnóstico baseada em hipertermia e administração controlada de medicamentos. Modificado de Kumar and Mohammad (2011).

\section{MATERIAIS E MÉTODOS}

Materiais: Os reagentes telúrio metálico, borohidreto de sódio, perclorato de cádmio, ácido mercaptosuccínico (AMS), Nhidroxisulfosuccinimida (sulfo- $\mathrm{NHS}$ ), cloreto ferroso $\left(\mathrm{FeCl}_{2} \cdot 4 \mathrm{H}_{2} \mathrm{O}\right)$, cloreto férrico $\left(\mathrm{FeCl}_{3} .6 \mathrm{H}_{2} \mathrm{O}\right)$, hidróxido de amônio $\left(\mathrm{NH}_{4} \mathrm{OH}\right)$, permanganato de potássio $\left(\mathrm{KMnO}_{4}\right)$, 1-etil-3-(3-dimetilaminopropil) carbodiimida (EDC) e anilina foram adquiridos da Sigma-Aldrich. Todos os outros reagentes utilizados neste trabalho foram de elevada pureza e disponíveis comercialmente.

Métodos:

Síntese de Quantum dots - A preparação dos PQs de telureto de cádmio estabilizados com o ácido mercaptosuccínico (CdTe-AMS) foi realizada conforme reportado por Cabral Filho et al. 2016. Posteriormente, as propriedades ópticas dos PQs foram avaliadas por espectroscopia de absorção eletrônica e emissão utilizando respectivamente o espectrofotômetro UV-VIS (UV-1800, Shimadzu) e o espectrofluorímetro PerkinElmer LS 55.

Síntese do ferrofluido - 0 processo de síntese das nanopartículas de óxido de ferro em suspensão (ferrofluido, FF) foi segundo Cabrera et al. 2017. Brevemente, as nanopartículas magnéticas foram obtidas pelo método de co-precipitação alcalina de sais de ferro (II) e (III). Para isto, soluções de $\mathrm{FeCl}_{2} \cdot 4 \mathrm{H}_{2} \mathrm{O}$ e $\mathrm{FeCl}_{3} \cdot 6 \mathrm{H}_{2} \mathrm{O}$ (2:3) foram mantidas sob agitação e em seguida, se adicionou o 
agente precipitante $\left(\mathrm{NH}_{4} \mathrm{OH}\right)$ até a mistura atingir $\mathrm{pH}$ 11. A solução permaneceu sob agitação em um banho ultrassônico a $50{ }^{\circ} \mathrm{C}$ por 30 minutos. Lavagens com água destilada do material obtido foram realizadas até alcançar $\mathrm{pH}$ neutro. Finalmente, o FF sintetizado foi armazenado a $4{ }^{\circ} \mathrm{C}$ para posterior uso. Antes do processo de funcionalização e com o intuito de aprimorar a estabilidade do sistema magnético, o $\mathrm{FF}$ foi tratado com três agentes estabilizantes: citrato de sódio $(\mathrm{CNa})$, metasilicato de sódio $(\mathrm{MNa})$ e ácido cítrico (ACit). Para isto, em um tubo falcon de $50 \mathrm{~mL}$ contendo uma alíquota do $\mathrm{FF}$ foram adicionados $25 \mathrm{~mL}$ do agente estabilizante. Em seguida, a solução resultante foi colocada sob agitação a $50{ }^{\circ} \mathrm{C}$ por 2 horas. Para obter uma melhor dispersão do sistema magnético, a solução foi colocada em um banho ultrassô nico por cerca de 2 horas.

Funcionalização do ferrofluido com polianilina (FF-PANI) - O FF tratado com $O$ agente estabilizante foi revestido com polianilina (PANI) com o objetivo de funcionalizar a superfície do núcleo magnético com grupos amina. 0 processo de síntese da PANI foi por oxidação química empregando o monômero anilina. Primeiramente, o FF foi tratado com o agente oxidante permanganato de potássio $(0,1 \mathrm{M})$ e mantido sob agitação por um período de 1 hora a $25{ }^{\circ} \mathrm{C}$. Posteriormente, o material magnético foi lavado (10x) com água destilada e em seguida adicionou-se solução de anilina $(0,25 \mathrm{M})$ preparada em $\mathrm{HCl}(2 \mathrm{M})$. 0 material foi colocado novamente sob agitação por 30 minutos a $4{ }^{\circ} \mathrm{C}$. Por fim, realizaram-se lavagens com água destilada e ácido clorídrico. $0 \mathrm{FF}$ revestido com polianilina (FF-PANI) obtido foi armazenado a $4{ }^{\circ} \mathrm{C}$ para posterior uso.

Preparação do sistema bimodal (BNPs) - O FF revestido com polianilina (FF-PANI) foi utilizado como suporte para a conjugação covalente aos PQs de CdTe-AMS. Para propiciar a ligação covalente entre o material magnético estabilizado/funcionalizado com grupos amina e os PQs estabilizados/funcionalizados com grupos carboxí licos foram utilizados os agentes de acoplamento: EDC/sulfo-NHS. Assim, os PQs de CdTe-AMS ( $1 \mathrm{~mL}$ ) foram ativados com EDC/sulfoNHS $\left(4,4 \mathrm{mg} \mathrm{mL}^{-1} / 5,5 \mathrm{mg} \mathrm{mL}^{-1}\right)$ sendo o $\mathrm{pH}$ ajustado entre 5 - 6 com AMS e logo foram adicionados à suspensão de FF-PANI. 0 sistema permaneceu então sob agitação por 24 horas a $25^{\circ} \mathrm{C}$. Após este período, amostra do sobrenanate $(\mathrm{Sb})$ foi coletada com ajuda de um campo magnético externo (ímã de neodímio, $\mathrm{NdFeB}$ ). Os sistemas e também o processo de conjugação foram avaliados através de espectroscopia de absorção eletrônica e fluorescência através dos mesmos equipamentos utilizados na caracterização dos PQs. O potencial zeta (Malvern Zetasizer) também foi utilizado para determinar a carga líquida da superfície dos materiais nanoparticulados obtidos. Este parâmetro auxiliou na compreensão dos processos de dispersão e agregação das nanopartículas magné ticas. Portanto, análises de potencial zeta foram realizadas para avaliar a estabilidade dos sistemas magnéticos bem como para verificar os processos de modificação na superfície das nanopartí culas magnéticas.

\section{RESULTADOS E DISCUSSÃO}

A funcionalização adequada da superfície das nanopartículas e a escolha do solvente são cruciais para as interações repulsivas entre as nanopartículas, suficientes para prevenir a agregação e se obter uma solução coloidal termodinamicamente estável. Segundo Sousa et al. 2013, o tratamento de núcleos magnéticos com pequenas moléculas orgânicas biocompatíveis (aminoácidos, peptídeos, ácido cítrico e ciclodextrina) permite obter um material com funcionalidade para a conjugação de biomoléculas e biocompatí vel, além de combinar estabilização eletrostática e estérica. Neste trabalho foram avaliados três agentes estabilizantes (ácido cítrico, citrato de sódio e metasilicato de sódio). Após o tratamento do FF com os agentes estabilizantes foi notável que esse processo promoveu à melhoria da estabilidade dos sistemas magnéticos. 0 mecanismo de ação do ACit e do seu sal correspondente, o $\mathrm{CNa}$, foi através de processos de coordenação, onde o ácido cítrico é coordenado através de um ou dois dos grupamentos carboxílicos, dependendo da necessidade estérica e da curvatura da superfície. Provavelmente, o $\mathrm{MNa}$ apresentou um comportamento semelhante. As análises de potencial zeta foram essenciais para avaliar a estabilidade dos sistemas magnéticos bem como para avaliar os processos de modificação na superfície das nanopartí culas magnéticas. A Tabela 1 apresenta os resultados obtidos desta análise para o FF (controle), o FF estabilizado com três moléculas orgânicas, o FF funcionalizado com PANI e o sistema bimodal obtido (FF estabilizado com ácido cítrico, funcionalizado com PANI e conjugado com PQs de (dTe-AMS). O FF apresentou um potencial zeta negativo $(-13,9 \mathrm{mV})$ devido à presença de grupamentos hidroxila $\left(\mathrm{OH}^{-}\right)$na superfície deste material. Após o processo de tratamento com os agentes estabilizantes foi observada uma diminuição do módulo do potencial zeta mais acentuada para o á cido cítrico quando comparado com o ferrofluido nu, por isso esse foi o sistema escolhido para a modificação com PANI. O tratamento com PANI propiciou uma mudança na carga líquida do material magnético. $O$ potencial zeta positivo $(+41,4 \mathrm{mV})$ do FFACit-PANI é um indício que o revestimento com PANI foi realizado com sucesso e consequentemente grupos amina $\left(-\mathrm{NH}_{2}\right)$ estão presentes na superfície do material magnético. A conjugação covalente dos PQs ao FF-ACit-PANI foi também evidenciada pela variação do potencial zeta no sistema bimodal. A carga líquida da superfície das nanopartículas FF-ACit-PANI sofreu alteração, passou de carga positiva para carga negativa, devido à presença de grupos carboxílicos ( $\left.\mathrm{COO}^{-}\right)$aportados pelos PQs. Desta maneira, foi possí vel corroborar também que o processo de conjugação com os PQs foi satisfatório.

A confirmação da conjugação covalente dos PQs nas nanopartículas de FF-ACit-PANI foi também evidenciada através da espectroscopia de absorção. Logo após o processo de conjugação, uma amostra do sobrenadante $(\mathrm{Sb})$ do sistema bimodal foi coletada com o objetivo de fazer a caracterização óptica e verificar se a conjugação tinha ocorrido. Na Figura 2a, é possível observar para a suspensão de PQs de CdTe-AMS um máximo de absorção aproximadamente em 560 $\mathrm{nm}$. Nesse comprimento de onda os PQs apresentaram um tamanho próximo dos $3 \mathrm{~nm}$ (Dagtepe et al., 2007). 0 perfil do espectro de absorção referente ao sobrenadante (linha azul) permitiu concluir que o processo de conjugação foi realizado com sucesso. Baixos valores de absorbância (ausência do máximo de absorbância em $560 \mathrm{~nm}$ ) foi encontrado para o sobrenadante do sistema bimodal. Este resultado indicou que praticamente todos PQs ofertados ficaram conjugados covalentemente nas nanopartículas de FF-ACitPANI.

Tabela 1. Potencial zeta das amostras magnéticas modificadas.

\begin{tabular}{lcc}
\hline \multicolumn{1}{c}{ Amostra } & $\begin{array}{c}\text { Média do potencial } \\
\text { zeta }(\mathrm{mV})\end{array}$ & Desvio Padrão $(\mathrm{mV})$ \\
\hline FF (Controle) & $-13,9$ & 5,5 \\
FF-CNa & $-18,0$ & 3,8 \\
FF-MNa & $-20,8$ & 6,5 \\
FF-ACit & $-21,1$ & 6,4 \\
FF-ACit-PANI & $+41,4$ & 3,9 \\
FF-ACit-PANI-CdTe-AMS & $-13,4$ & 4,9 \\
\hline
\end{tabular}

A Figura $2 \mathrm{~b}$ apresenta a fluorescência normalizada dos PQs de CdTe-AMS e do sistema bimodal obtido. O CdTe-AMS teve o máximo de fluorescência próximo de $590 \mathrm{~nm}$, porém quando foram conjugados às nanopartículas magnéticas de FF-ACit-PANI, observou-se um deslocamento batocrômico (red shift) do máximo de emissão de aproximadamente $40 \mathrm{~nm}$. 0 espectro de emissão do sistema bimodal apresentou um pico estreito com comprimento de onda máximo em $630 \mathrm{~nm}$ e largura à meia altura de $44 \mathrm{~nm}$. 
Provavelmente, esse deslocamento seja um indício da modificação de superfície. Cabrera et al., 2017 reportaram um sistema bimodal altamente fluorescente e superparamagnético a partir de ferrofluido modificado com o agente silano 3aminopropriltrietoxisilano (APTES), diâmetro médio de $15 \mathrm{~nm}$, conjugado covalentemente a PQs de CdTe-AMS ( $3 \mathrm{~nm})$. Os autores caracterizaram o sistema bimodal obtido como um promissor agente de contraste para IRM devido a boa relaxividade e magnetização. Além disso, a magnetita foi encontrada como a fase predominante do núcleo magnético. Neste presente trabalho com PANI foram utilizadas as mesmas nanopartículas de óxido de ferro reportadas por Cabrera et al., 2017.
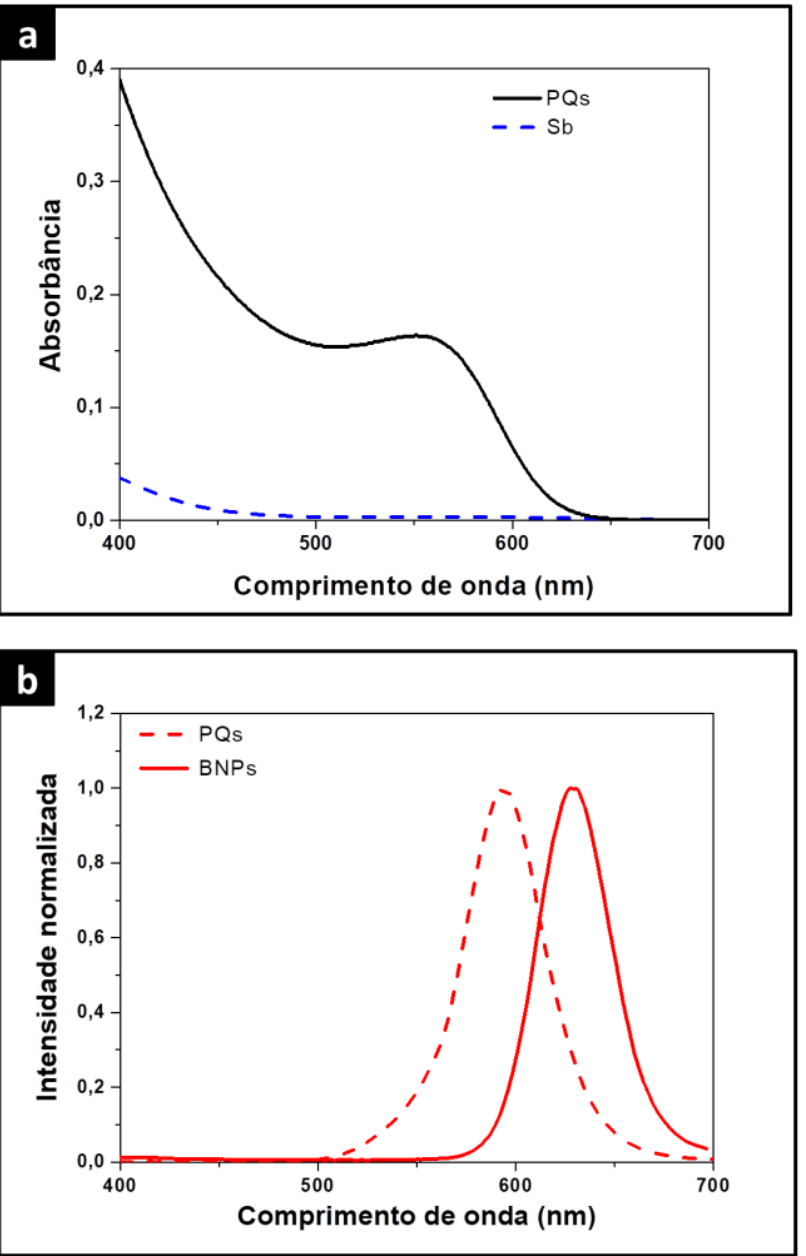

Figura 2. (a) Espectros de absorção dos PQs de CdTe-AMS e do sistema bimodal (FF-ACitPANI-CdTe-AMS). A linha preta representa os PQs de CdTe-AMS ofertados e a linha azul o sobrenadante. (b) Espectros de fluorescência normalizados da suspensão de PQs de CdTeAMS (linha vermelha pontilhada) e do sistema bimodal (linha vermelha). 0 comprimento de onda de excitação utilizado foi $365 \mathrm{~nm}$.

Por fim, o sistema bimodal (FF-ACit-PANI-CdTe-AMS) apresentou uma boa resposta magnética frente à aplicação do campo magné tico externo (NdFeB), bem como uma resposta fluorescente quando excitados com lâmpada UV $365 \mathrm{~nm}$. Destaca-se que o sistema bimodal preservou as propriedades magneto-fluorescentes por um período de um ano.

\section{CONCLUSÕES}

As estratégias de estabilização utilizando os agentes estabilizantes (ACit, $\mathrm{CNa}$ e $\mathrm{MNa}$ ) assim como a funcionalização com polinanilina mostraram-se efetivas uma vez que foram obtidos sistemas nanoestruturados estáveis e com boa dispersão. A etapa da conjugação dos PQs de CdTe-AMS às nanopartículas magnéticas (FF-ACit-PANI) foi realizada com sucesso. 0 sistema bimodal apresentou boas propriedades magneto-fluorescentes e mostrou-se promissor para possíveis aplicações biológicas tais como agentes de contraste para IRM e como sondas para obtenção de imagens ó pticas. Além disso, a nova nanossonda poderá apresentar potencial atividade terapêutica gerada pelas propriedades magnéticas do ó xido de ferro, sendo portanto um novo agente nanoteranóstico. Té cnicas de separação e biossensores estão entre as outras possíveis aplicações do sistema bimodal.

\section{REFERÊNCIAS}

BAIRAGI, V. K.; ASHOK M. S.; ANKITA T. Texture-Based Medical Image Compression. Journal of Digital Imaging, v.13, n.2, p. 6571, 2012.

CABRAL FILHO, P. E.; CARDOSO, A. L. C.; PEREIRA, M. I. A.; RAMOS, A. P. M.; HALLWASS, F.; CASTRO, M. M. C. A.; GERALDES, C. F. G. C.; SANTOS, B. S.; PEDROSO DE LIMA, M. C.; PEREIRA, G. A. L.; FONTES, A. CdTe quantum dots as fluorescent probes to study transferrin receptors in glioblastoma cells. Biochimica et Biophysica Acta (BBA) - General Subjects, v. 1860, p. 28-25, 2016.

CABRERA, M. P.; CABRAL FILHO, P. E.; SILVA, C. M. C. M.; OLIVEIRA, R. M.; GERALDES, C. F. G. C.; CASTRO, M. M. C. A.; COSTA, B. F.; HENRIQUES, M. S. C.; PAIXÃO, J. A.; CARVALHO JR, L. B.; SANTOS, B. S.; HALLWASS, F.; FONTES, A.; PEREIRA, G. A. L. Highly fluorescent and superparamagnetic nanosystem for biomedical applications. Nanotechnology, v. 28, p. 285704, 2017. DAGTEPE, P., CHIKAN, V., JASINSKI, J., LEPPERT, V. J. Quantized Growth of CdTe Quantum Dots; Observation of Magic-Sized CdTe Quantum Dots. The Journal of Physical Chemistry C, v. 111, p. 14977-14983, 2007.

KUMAR, C. S.; MOHAMMAD F. Magnetic nanomaterials for hyperthermia-based therapy and controlled drug delivery. Advanced Drug Delivery Reviews, v. 63, p. 789-808, 2011.

MAIDMENT, A. D. A. The Future of Medical Imaging. Radiation Protection Dosimetry, v. 139, n. 1-3, p. 3-7, 2010.

PEREIRA, C.; PEREIRA, A. M.; ROCHA, M.; FREIRE, C.; GERALDES, C. F. G. C. Architectured design of superparamagnetic $\mathrm{Fe}_{3} \mathrm{O}_{4}$ nanoparticles for application as MRI contrast agents: mastering size and magnetism for enhanced relaxivity. Journal of Materials Chemistry B, v. 3, p. 6261-6273, 2015.

SANTOS, B. S.; FARIAS, P.M.A; FONTES, A.; BRASIL JR, A.G.; JOVINO, C.N.; NETO, A.G.; SILVA, D.C.N.; F.D. DE MENEZES, FERREIRA, R. Semiconductor nanocrystals obtained by colloidal chemistry for biological applications. Applied Surface Science, v. 255, p. 796-798, 2008.

SOUSA, M. E.; FERNANDEZ VAN RAAP, M. B.; RIVAS, P. C.; ZELIS, P. M.; GIRARDIN, P.; PASQUEVICH, G. A.; ALESSANDRINI, J. L.; MURACA, D.; SANCHEZ, F. H. Stability and Relaxation Mechanisms of Citric Acid Coated Magnetite Nanoparticles for Magnetic Hyperthermia. The Journal of Physical Chemistry C, v. 117, p. 5436-5445, 2013. 